\title{
Siphunculina quinquangula (Loew) (Diptera, Chloropidae) new to Japan: Emergence from the remains stage of pig carcass, with the implications for forensic entomology
}

\author{
Mitsuhiro IwasA $^{*, 1)}$, Shohei OIKAwA ${ }^{1)}$ and Kenkichi KanmiYA ${ }^{2)}$ \\ *Corresponding author: Laboratory of Entomology, Obihiro University of Agriculture and \\ Veterinary Medicine, Obihiro, Hokkaido 080-8555, Japan (E-mail: iwasa@obihiro.ac.jp) \\ 1) Laboratory of Entomology, Obihiro University of Agriculture and Veterinary Medicine, \\ Obihiro, Hokkaido 080-8555, Japan \\ ${ }^{2)}$ Institute of Comparative Studies of International Cultures and Societies, Kurume University, \\ Mii-machi, Kurume, Fukuoka 839-0851, Japan
}

(Received: 5 October 2012; Accepted: 10 December 2012)

\begin{abstract}
A chloropid species, Siphunculina quinquangula (Loew, 1873) is recorded for the first time from Japan. Adult flies were collected in emergence traps covered on the remains stage of an exposed pig carcass. The implications are given for S. quinquangula (Loew) in estimating postmortem periods for forensic entomology. A key to the known Japanese species of the Siphunculina is also provided.
\end{abstract}

Key words: Diptera, Chloropidae, Siphunculina quinquangula, new record, pig carcass, forensic entomology, Japan

\section{INTRODUCTION}

The flies of the genus Siphunculina Rondani are widely distributed in the world, comprising 35 species except for South America (Sabrosky, 1977, 1980, 1989; Nartshuk, 1984; Kanmiya, 1989). In the Oriental and Palaearctic regions, 15 and 8 species have been recorded, respectively (Kanmiya, 1989, 1994; Ismay and Nartshuk, 2000). The larvae are scavenging or scatophagous (Kanmiya, 1983). Adults of some species are well known as "eye fly", and they transmit conjunctivitis and other diseases to man and domestic animals (Graham-Smith, 1930). In Japan, 7 species were recorded by Kanmiya $(1982,1989)$, but since then there has been no record of other species in this genus.

During a recent survey of fly succession patterns in exposed pig carcass in Hokkaido, we collected an unrecorded species of the genus Siphunculina Rondani in Japan. This species here identified as $S$. quinquangula (Loew) is recorded for the first time from Japan. We give some bionomics with the implications as forensic indicator for the remains stage in postmortem interval of exposed carcasses. A key to the species of the Siphunculina in Japan is also provided.

\section{Materials And Methods}

On 24 June 2011, the carcass of a pig (weight $18 \mathrm{~kg}$ ) was placed at a forested area near the Campus of Obihiro University of Agriculture and Veterinary Medicine. The carcass was covered by an enclosure cage (length $90 \mathrm{~cm} \times$ width $120 \mathrm{~cm} \times$ height $60 \mathrm{~cm}$ ) made of wire mesh $(2.5 \mathrm{~cm} \times 2.5 \mathrm{~cm})$ to keep out vertebrate scavengers. The decomposition process of the carcass was divided into 5 stages on the basis of the classification by Payne (1965): fresh stage (days 0-3), bloated stage (days 3-5), active decay stage (days 5-9), advanced decay stage (days 9-12), and remains stage (days 12-). On day 17 , the cage was removed, and bones and bits of skin were covered by two emergence traps (length $28 \mathrm{~cm} \times$ width $28 \mathrm{~cm} \times$ height $70 \mathrm{~cm}$ ). Flies that emerged in the emergence traps were checked daily until 64 days after the covering trap. Adults that emerged were identified as Siphunculina quinquangula (Loew) by one of us (Kanmiya, K.).

\section{DESCRIPTION}

Siphunculina quinquangula (Loew, 1873) Japanese name: Kiashi-mematoi-kimoguribae

(Figs. 1-7)

Siphonella quinquangula Loew, 1873: Berl. ent. Z. 17: 51.

Siphunculina quinquangula: Nartshuk, 1984: Catalog. Palae. Dipt. 10: 256.

Male (Fig. 1). Head: wholly black; frontal triangle large, matt black, and its apex reaching anterior margin of frons (Fig. 2); frons matt blackish brown; antennae black, with 3rd segment triangular-shaped (Figs. 1, 2), basoventrally orange; arista pubescent; proboscis long, slender and geniculate; palpi slender and yellow: cephalic setae and hairs all black; 2 or, 4-5 if, 1 vte, 1 pvt. Thorax: entirely black; mesonotal dorsum matt brownish-gray pruinose, very shagreened, clothed with minute $a c$ and $d c$ and pubescence entirely black; scutellum also matt black, brownish-gray pruinose; ap sc well 


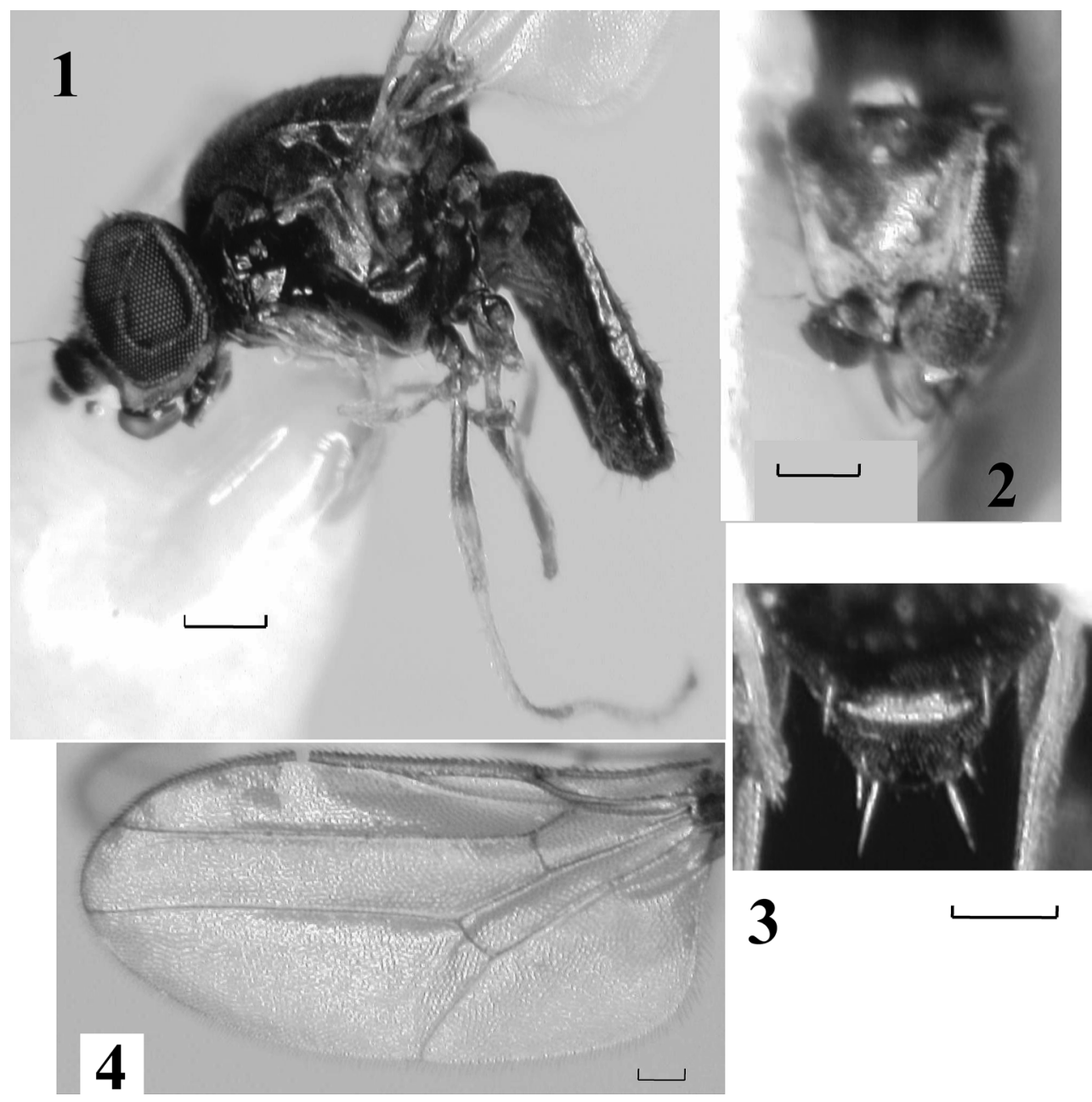

Figs. 1-4. Siphunculina quinquangula (Loew), male. 1: body, lateral view, 2: head, dorsal, 3: scutellum, dorsal, 4: right wing, underside. Scale bars: $0.1 \mathrm{~mm}$.

separated each other, widely divergent, about $5 / 8 \times$ as long as scutellum (Fig. 3): 2 pairs of sbap sc very short. Thoracic pleura entirely black, with proepisternum, anepisternum, and katepisternum bare and glossy; anepimeron and meron gray-white pruinose; $1 d c, 2 n, 1$ pa. Wings (Fig. 4) hyaline, slightly tinged with brown; veins light brown; $R_{2+3}$ extremely short and cell $r_{1}$ narrow; second costal sector much shorter than third sector; halteres black on knob. Legs: fore coxae, femora and tibiae yellow; mid coxae black; basal half of mid femora brown; distal half of mid femora and tibiae yellow; hind coxae black; basal half of hind femora dark brown; distal half of hind femora and hind tibiae yellow; all tarsal segments yellow, darkened apically. Abdomen: wholly black; tergites shining, densely covered with minute setulae; epandrium (Fig. 5) developed, covered with setulae; surstyli (Fig. 6) stout, broad, apically rounded, orienting inward; cerci small, not fused at bases; hypandrium (Fig. 7) narrow, simple and horseshoe form; aedeagus greatly reduced and indistinct; aedeagal apodome (Fig.7) pigmented and beyond hypandrial margin.

Female. Terminalia simple; cerci evident as a pair of pendant lobes with long hairs. Other characteristics same as those of male.

Length: body (주우), $1.3-1.6 \mathrm{~mm}$; wings, $1.3^{-}$ $1.5 \mathrm{~mm}$.

Specimens examined. 37 기, 47 우, 2-6 August 2011, Obihiro, Hokkaido, Japan, S. Oikawa leg.

Distribution. Austria, Hungary, Latvia, Poland, Rumania, Ukraina (Nartshuk, 1984) and Japan. New to Japan.

Remarks. This species is distinguishable from other congeneric species of Japan by having the 3rd antennal segment somewhat triangular on dorsodistal corner, large frontal triangle matt blackish brown, its apex extending to anterior margin of frons, as well as mesonotal dorsum and scutellum evenly matt black with brownish-gray pruinosity.

\section{Bionomics with the implications for forensic entomology}

The larvae of the Siphunculina species are known to be scavengers; S. aenea (Macquart) is coprophagous, and was reared from dung of brown bears (Ursus arctos yezoensis) and cow dung, and S. nidicola Nartshuk was 

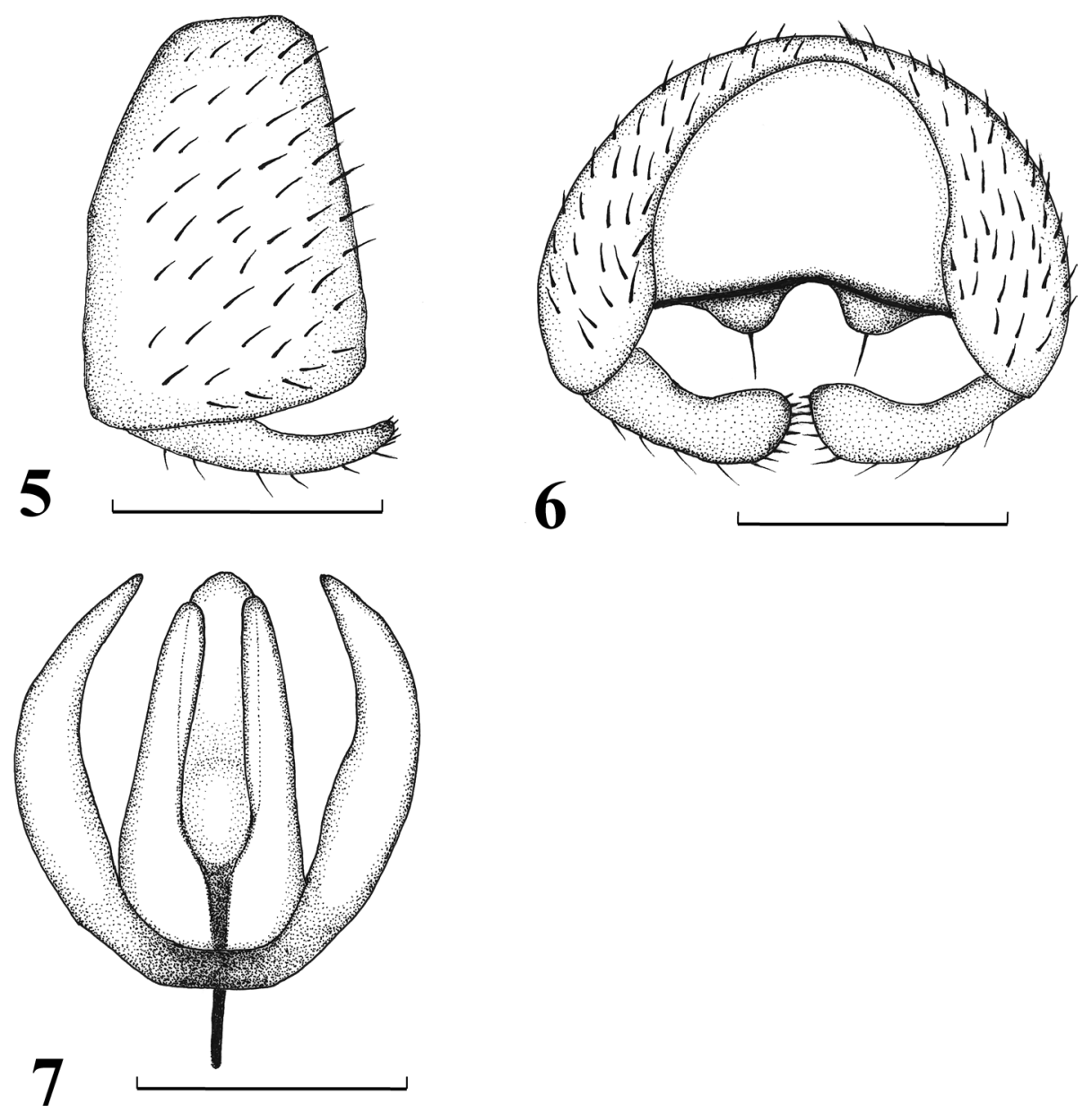

Figs. 5-7. Siphunculina quinquangula (Loew), male genitalia. 5: epandrium and surstylus in lateral vew, 6: epandrium and surstylus, in posterior view, 7: hypandrium and phallic complex in ventral view. Scale bars: $0.1 \mathrm{~mm}$.

reared from bird nest of heron (Ardeidae) (Kanmiya, 1982, 1983). Some larvae are necrophagous, feeding on dead animals (Ismay and Nartshuk, 2000). Acalypterate flies associated with dead bodies or carcasses of animals and humans were reviewed by Smith (1986) in point of view for forensic entomology, and it has been reported that Phoridae, Poiphilidae, Scatopsidae, Sepsidae, Psychodidae, and Sphaeroceridae occur in the latter part of the decay stage or the remains stage of carcasses (Smith, 1986; Early and Goff, 1986; Tullis and Goff, 1987; Tantawi et al., 1996;). There is, however, little information on the necrophagous chloropid species. In the present survey of fly succession in an exposed pig carcass, adults of $S$. quinquangula with adults of some species of Piophilidae were collected in large numbers during 39-43 days after exposing a carcass in emergence traps covered on the remains stage which is characterized by bones and bits of skin. This result suggests that the larvae of $S$. quinquangula as well as piophilid species develop in bones or bits of remaining skin, and that this species may useful as a forensic indicator to estimate postmortem time in the remains stage of exposed carcasses. Detailed fly succession patterns in exposed pig carcasses will be described in a separate paper.

\section{Key to the Japanese species of Siphunculina (o'우)}

1. Third antennal segment with somewhat angular dorsodistal corner which is extending apically, much deeper than long......S. quinquangula (Loew)

- Third antennal segment with rounded dorsodistal corner..........................................................................

2. Cephalic setae and hairs and mesonotal hairs black or dark-brown..................................................

- Cephalic setae and hairs and mesonotal hairs pale-yellow, golden-yellow, or brassy yellow..........6

3. Frontal triangle not entirely polished, with pruinosity partially or entirely.

- Frontal triangle except for ocellar tubercle entirely polished, without any puruinosity; frons, frontal triangle, and mesonotum marked out by reticulate patterns with alternating puruinose and bare maculae.................................... striolata (Wiedemann)

4. Frontal triangle with apex nearly or completely reaching anterior margin of frons...

- Frontal triangle with apex ending slightly but distinctly before anterior margin of frons.

5. Frontal triangle large with somewhat convex sides; wing with 3 rd costal sector about $2.2-2.75 \times$ as 
long as 2nd sector in male; mid and hind tibiae yellow with median black maculae.

S. aenea (Macquart)

- Frontal triangle narrow with straight sides; 3rd costal sector about $3-4 \times$ as long as 2 nd sector in male; mid and hind tibiae largely blackened except for both ends yellow.............S. nitidissima Kanmiya

6. Frontal triangle largely covered with pruinosity, but with small polished areas at vertex, in front of ocelli, or at anterior apex....... ....7

- Frontal triangle entirely covered with pruinosity and matt; frons dark-brown behind and yellowish-brown in front .......................S. saigusai Kanmiya

7. Frontal triangle smooth with distinctly pruinose areas; 2 pairs of scutellar setae.

S. nidicola Nartshuk

- Frontal triangle matt, punctuate, mostly covered with pruinosity, only with polished areas in front of ocelli to apex and on both narrow lateral parts of ocellar tubercle; 3 pairs of scutellar setae. S. simulata Kanmiya

\section{ACKNOWLEDGEMENTS}

We wish to offer our sincere thanks to Assistant Professor G. A. Hill of Obihiro University of Agriculture and Veterinary Medicine for checking the English of this manuscript.

\section{REFERENCES}

Early, M. and Goff, M. L. 1986. Arthropod succession patterns in exposed carrion on the island of O'ahu, Hawaiian Islands, USA. J. Med. Entomol., 23: 520-531.

Graham-Smith, G. S. 1930. The Oscinidae (Diptera) as vectors of conjunctivitis, and the anatomy of their mouth parts. Parasitology, 22: $457-467$.
Ismay, J. W. and Nartshuk, E. P. 2000. A.11. Family Chloropidae. In: Contribution to a Manual of Palaearctic Diptera (ed. Papp, L. and Darvas, B.) Appendix, pp. 387-429. Science Herald, Budapest.

Kanmiya, K. 1982. Two new species and three new records of the genus Siphunculina Rondani from Japan (Diptera: Chloropidae). Jpn. J. Sanit. Zool., 33: 111-121.

Kanmiya, K. 1983. A systematic study of the Japanese Chloropidae (Diptera). Mem. Entomol. Soc. Wash., No.11, 370 pp. Entomol. Soc. Wash., Washington, D. C.

Kanmiya, K. 1989. Study on the eye-flies, Siphunculina Rondani from the Oriental Region and Far East (Diptera, Chloropidae). Jpn. J. Sanit. Zool., 40 (Suppl.): 65-86.

Kanmiya, K. 1994. Studies on the eye-flies Siphunculina Rondani from Nepal (Diptera: Chloropidae). Jpn. J. Sanit. Zool., 45 (Supplement): 55-69.

Nartshuk, E. P. 1984. Family Chloropidae. In: Catalogue of Palaearctic Diptera (ed. Soós, A. and Papp, L.). Vol. 10, pp. 222-299. Akadémiai Kiadó, Budapest.

Payne, J. A. 1965. A summer carrion study of the baby pig Sus scrofa Linnaeus. Ecology, 46: 592-602.

Sabrosky, C. W. 1977. Family Chloropidae. In: A Catalogue of the Diptera of the Oriental Region (ed. Delfinado, M. D. and Hardy, D. E). 3. Suborder Cyclorrhapha (excluding division Aschiza), pp. 277-319. Univ. Press Hawaii, Honolulu.

Sabrosky, C. W. 1980. 80. Family Chloropidae. In: Catalogue of the Diptera of the Afrotropical Region (ed. Crosskey, R. W.). pp. 695712. British Museum (Nat. Hist.), London.

Sabrosky, C. W. 1989. 100. Family Chloropidae. In: Catalog of the Diptera of the Australasian and Oceanian Regions (ed. Evenhuis, N.). Bishop Museum Special Publication, 86, pp. 650-665. Bishop Museum Press and E. J. Brill, Honolulu.

Smith, K. G. V. 1986. A Manual of Forensic Entomology. 205 pp. British Museum (Nat. Hist.), London, and Cornell University of Press, Ithaca, New York.

Tantawi, T. I., El-Kady, E. M., Greenberg, B. and El-Ghaffar, H. A. 1996. Arthropod succession on exposed rabbit carrion in Alexandria, Egypt. J. Med. Entomol., 33: 566-580.

Tullis, K. and Goff, M. E. 1987. Arthropod succession in exposed carrion in a tropical rain forest on O'ahu Island, Hawaii. J. Med. Entomol., 24: 332-339. 